\title{
Effects of aquaculture on the shallow lake aquatic ecological environment of Lake Datong, China
}

\author{
Wen $\mathrm{Hu}^{1,2 \dagger}$, Chun-hua Li ${ }^{1 \dagger}$, Chun Ye ${ }^{1 *}\left(\mathbb{0}\right.$, Hong-sen Chen ${ }^{1}$, Jun $\mathrm{Xu}^{3}$, Xu-hui Dong ${ }^{4}$, Xiao-shou Liu ${ }^{5}$ and \\ Deliang $\mathrm{Li}^{6}$
}

\begin{abstract}
Background: The restoration of lake ecosystems requires a good knowledge of the lake's history and the driving mechanism of environmental changes. In this study, we used Lake Datong, the largest inland lake in Hunan Province China, as an example to study the effects of aquaculture, based on historical data of aquatic creature, diatom inferredtotal phosphorous (DI-TP) data, and an Ecopath model. Lake Datong has undergone several stages of aquaculture from 1980, with a rapid increase in fish production and fish feed supplementation at each stage. Its water quality has deteriorated since the introduction of aquaculture and the lake has become moderate eutrophic status.
\end{abstract}

Results: According to the DI-TP data, before 1930, Lake Datong was in a mesotrophic status (50-60 $\mathrm{\mu g} / \mathrm{L}$ DI-TP). Between 1930 and 1980, the number of nutrient-tolerant species increased slightly, which indicates a nutrient increase in the lake (66-83 $\mu \mathrm{g} / \mathrm{L}$ DI-TP). From the 1980s to 2010 and especially since 2000, eutrophication increased rapidly, with eutrophic species dominating the diatom assemblage, such as Stephanodiscus hantzschii, S. minutulus, and a sudden decrease in Aulacoseira granulata (<10\%). The annual average DI-TP concentration was $202 \mu \mathrm{g} / \mathrm{L}$. After 2010, DI-TP decreased to 127-152 $\mathrm{\mu g} / \mathrm{L}$. In 2019, consumer biomass in Lake Datong was very low because the largescale aquaculture was restricted by local government. The biomass of submerged macrophytes was relatively high, indicating that excessive primary producers had not been used by consumers and therefore, had not entered the food web. This led to a reduction in the energy transfer efficiency (TE) of the ecosystem.

Conclusions: The succession of the water ecosystem of Lake Datong is reappeared by DI-TP analysis and historical reference data. Lake Datong has experienced four stages of eutrophication succession following the introduction of aquaculture activities, with dramatic changes in the composition and biomass of its aquatic creatures. After comprehensive management in 2017, the consumer biomass of Lake Datong was at a relatively lower level, and the biomass of submerged macrophytes was higher, meaning a large quantity of primary producers had not been used by consumers, thus had not entered the food web, which consequently reduces the energy TE of the ecosystem. Future management needs to pay attention to making a suitable macrophyte harvest plan, stocking herbivorous and omnivorous fish, and establishing rational fishing, which can not only enhance the energy flows and nutrient cycling of the ecosystem, but also improve the food web structure. Our results provide important reference values

\footnotetext{
*Correspondence: yechbi@163.com

'Wen Hu and Chun-hua Li contributed equally

${ }^{1}$ National Engineering Laboratory for Lake Pollution Control

and Ecological Restoration, State Environmental Protection Key

Laboratory for Lake Pollution Control, Chinese Research Academy

of Environmental Sciences, Beijing 100012, China

Full list of author information is available at the end of the article
}

\section{Springer Open}

(c) The Author(s) 2022 Open Access This article is licensed under a Creative Commons Attribution 4.0 International License, which permits use, sharing, adaptation, distribution and reproduction in any medium or format, as long as you give appropriate credit to the original author(s) and the source, provide a link to the Creative Commons licence, and indicate if changes were made. The images or other third party material in this article are included in the article's Creative Commons licence, unless indicated otherwise in a credit line to the material. If material is not included in the article's Creative Commons licence and your intended use is not permitted by statutory regulation or exceeds the permitted use, you will need to obtain permission directly from the copyright holder. To view a copy of this licence, visit http://creativecommons.org/licenses/by/4.0/. 
and theoretical support for decision-makers and stakeholders in the subsequent management of similar shallow lakewater ecosystems.

Keywords: Aquaculture, Succession, Aquatic creature, Eutrophication, Lake Datong, Food web, Ecopath model

\section{Introduction}

Aquaculture provides nearly $20 \%$ of the average daily protein intake of $\sim 3.1$ billion people across the world [1]. At present, nearly half $(45.2 \%)$ of the world's supply of aquatic products comes from farms, and the contribution of aquaculture and fisheries continues to increase annually [2]. China produces more aquaculture products than any other country, and it accounts for nearly two-thirds (62.1\%) of the total supply [2]. China produced 29.60 million of freshwater aquaculture products in 2018 and undertook lake aquaculture spanning $\sim 750,000 \mathrm{ha}$, which amounts to almost $15 \%$ of the total freshwater aquaculture area of China [3]. Lake aquaculture production is $980,000 \mathrm{t}$, which amounts to $~ 33 \%$ of the total freshwater aquaculture production in China [3]. In aquaculture, supplementary feed and fertilization are used to improve fish yield. However, in China, the feed utilization rate of aquaculture is low; when $100 \mathrm{~kg}$ of feed is used, $\sim 13-15 \mathrm{~kg}$ of the feed is not consumed and discharged directly into nearby surface water [4], while simultaneously, 20-30\% of the feed ingested by fish is indirectly discharged into the water through feces [5]. According to previous studies in the neighboring provinces of Lake Datong, the total nitrogen (TN) and total phosphorus (TP) concentrations in lake-water column were $219 \%$ and $150 \%$ higher in culture areas than in non-culture ones [6, 7], respectively. Such high TN and TP concentrations could cause the oxygen depletion, eutrophication, and turbidity of aquaculture lakes $[6,8-10]$.

Understanding the long-term impact of aquaculture on lake-water ecology is very important for the restoration of such lakes. Although the changes of water quality indicators over the years could be used for this aim, many lakes do not have enough water historical data. Therefore, more and more studies turned to using lake sediment to reflect the historical change of the lake [11-13]. Over the past two decades, several approaches have been developed to reconstruct past nutrient concentrations in lakes. These include reconstruction of in-lake total $P$ (TP) concentrations from sub-fossil diatoms preserved in lake sediments, and export coefficient modeling, which hindcasts export of $\mathrm{P}$ from catchment sources to surface waters, based on contemporary records of catchment use and management [14]. Diatoms are widely used for tracking environmental change [15-17] as they are sensitive to shifts in water quality and are good indicators of TP concentrations in lakes $[11,14,18]$. Transfer functions have been developed that describe the relationship between sediment diatom assemblage composition and lake-water TP concentration in a set of lakes known as a training set [19]. We hypothesized that the diatom inferred-TP (DI-TP) levels would closely reflect the human-induced events both in the lake and its catchment $[20,21]$. Combining the high-resolution of ${ }^{210} \mathrm{~Pb} /{ }^{137} \mathrm{Cs}$ dating technology and the analysis of various physical, chemical, and biological indices of sediments, we can effectively provide information on lake-water environment changes in historical periods [11]. Therefore, based on the investigations of the ecological environment of Lake Datong in 2019 combined with existing historical documents and the multiple proxy analysis including ${ }^{210} \mathrm{~Pb} /{ }^{137} \mathrm{Cs}$, losson-ignition (LOI), sediment TP, and diatoms from Lake Datong, we reconstructed the history of the local environment over the past 160 years.

Additionally, we constructed an Ecopath model to explore the status of the ecosystem during the restoration of eutrophic shallow lakes. This study reveals the water ecological succession law of Lake Datong, its time and variability of water quality degradation, and analyzes the leading factors of water ecological environment change. It provides a basis for shallow lake management after ecosystem restoration and may aid the management of similar shallow lakes throughout the world.

\section{Materials and methods}

\section{Study area}

The study area is Lake Datong, Hunan Province, China (Fig. 1), which is the largest inland lake in Hunan Province [22]. In the early 1950s, the original area of Lake Datong was $313.4 \mathrm{~km}^{2}$. After continuous reclamation, the lake surface gradually shrank, reaching the current lake area of $82.67 \mathrm{~km}^{2}$. The east-west and north-south distances of Lake Datong are 15.75 and $13.70 \mathrm{~km}$, respectively. The average water depth is $2.58 \mathrm{~m}$, and the maximum water depth is $2.94 \mathrm{~m}$. The lake area has a humid monsoon climate from mid-subtropical to north subtropical, with an average annual temperature of $16.6{ }^{\circ} \mathrm{C}$. The annual precipitation is $1237.7 \mathrm{~mm}$, of which $\sim 68 \%$ occurs from April to September. Lake Datong belongs to the Lake Dongting water system, and the water mainly relies on lake precipitation and surface runoff for replenishment. Three main channels are connected to Lake Datong: Daxin River, Laohe River (the intersection of Laosan and Saiyang Canals), and Wuqi Canal. The discharge ditches 


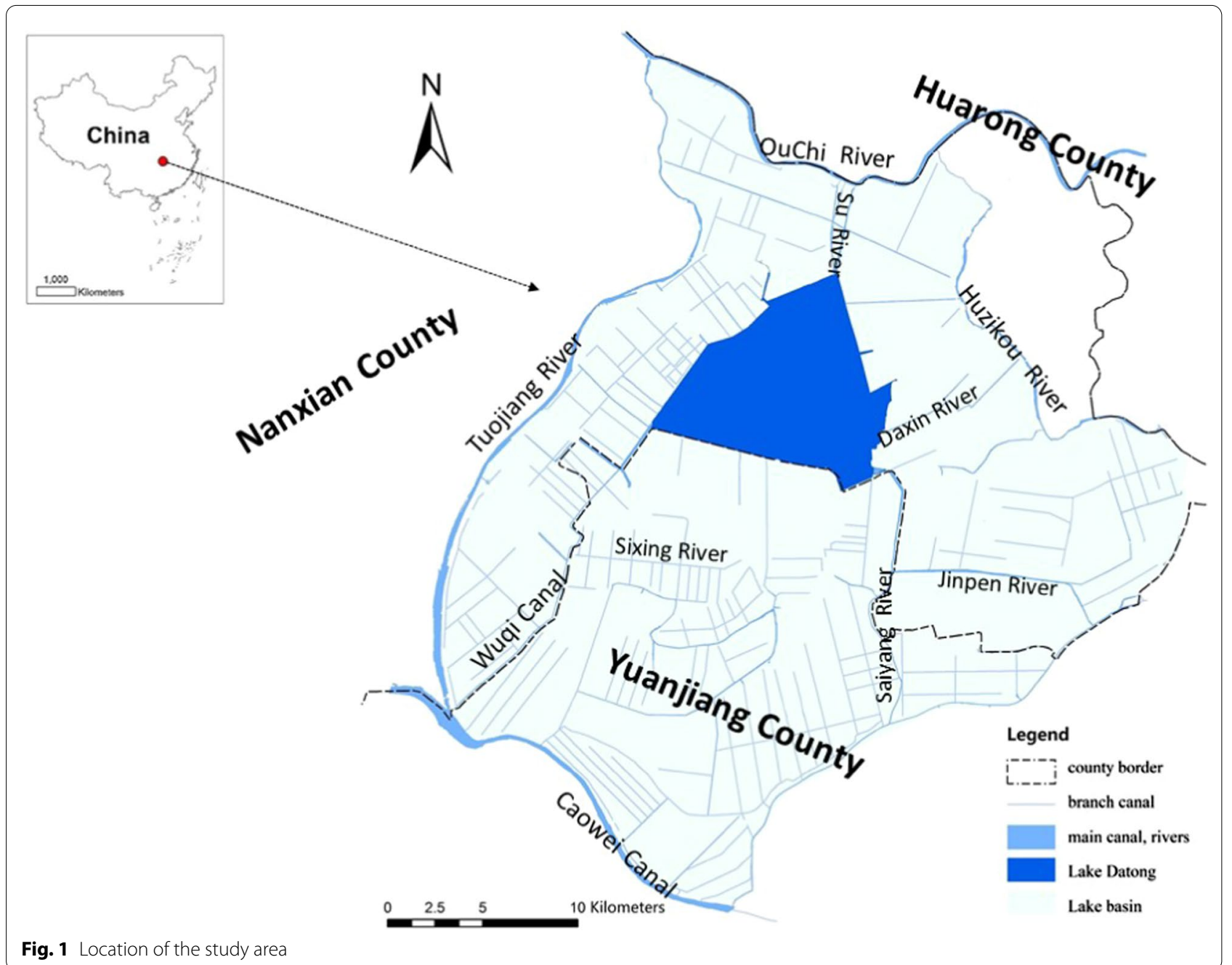

from farmlands of its watershed are connected to surrounding rivers and eventually flow into Lake Datong. The elevation of Lake Datong is lower than that of the surrounding areas, such that the lake area is thus a "sink" of non-point-source pollution [23].

Lake Datong has experienced from natural proliferation to high-density artificial cultivation, and then recently banning aquaculture. Before 1990, Lake Datong was in natural proliferation stage. After 1990, the fertilization and high-density fish culture technology were applied to get an increasing aquaculture output. Aquaculture activities have seriously degraded the water ecosystem of Lake Datong [24]. According to the Environmental Quality Standards for Surface Water of China, the water quality of Lake Datong was between 'Inferior' and 'Class V', especially TP was much inferior than Class V. Consequently, Lake Datong was specifically criticized by the Ministry of Ecology and Environment of the People's Republic of
China in 2016. Therefore, from 2017 a series of comprehensive pollution control and management measures was undertaken. The fish in Lake Datong was removed on great scale and macrophyte restoration was launched to improve the quality of water. By July 2019, the macrophytes were restored and covered over an area of 39.67 $\mathrm{km}^{2}$, which amounts to $48 \%$ of the total water surface area. But no harvest plan has been conducted yet, as that when the plant decayed, the leaf surface returned to the sediment, and some nutrients were released into the water column.

\section{Data collection}

Aquatic creatures' data were based on a survey conducted in 2019. Phytoplankton in the water was collected one liter of the sampled water and fixed in $15 \mathrm{~mL}$ Lugol's solution. After sedimentation for $48 \mathrm{~h}$, a concentrated liquid sample was collected and preserved in $5 \%$ formalin. To 
determine phytoplankton, $50 \mathrm{~mL}$ residue was collected after removing the supernatant $[25,26]$. In addition, zooplankton was collected $20 \mathrm{~L}$ of the sampled water was collected using a No. 25 plankton net (pore size, $64 \mu \mathrm{m}$ ). The concentrated samples were placed in $50 \mathrm{~mL}$ bottles fixed in $4 \%$ formaldehyde solution and transported to the laboratory in plastic bottles [27]. Phytoplankton and zooplankton were counted in a $0.1 \mathrm{~mL}$ counting chamber $(20 \mathrm{~mm} \times 20 \mathrm{~mm})$ using a microscope at a 400 times magnification lens. Mollusks were collected using mud samplers, then washed over $0.5-\mathrm{mm}$ screens, fixed in $75 \%$ ethanol solution, and transported to the laboratory in plastic bottles. The fish resource survey adopted separate collection points. The traditional fishing method was used with a gillnet and ground cage, where the individual surveys the lake using fishing boats to count fish species. Mollusk resource survey was conducted using Peterson mud harvesters. Macrophytes were collected using a self-made sampler. The aquatic creatures' data and water quality data of 20 sampling points investigated in 2019 were interpolated and analyzed by ArcGIS software, and the interpolation method was Kriging method (Fig. 2).
The biodiversity index was statistically analyzed using PRIMER 6.0. Water quality parameters and sediment TP were analyzed according to the Practical Manual of Environmental Monitoring Method Standards of China [28]. LOI was measured by placing the sample in a muffle furnace and burning it at $550{ }^{\circ} \mathrm{C}$ for $4 \mathrm{~h}$. The sediment total phosphorus was determined by the United States Leeman Labs Profile ICP-AES. Sediment diatom samples were treated with hydrochloric acid and hydrogen peroxide to prepare slices [15]. Here, species identification mainly follows the classification system of Krammer and Lange-Bertalot [29]. At least 300 grains were identified for each sediment sample [30].

\section{Dating method and sedimentary rate estimation}

The detailed methods were scribed in our previous papers $[30,31]$. Concisely, natural radionuclides ${ }^{210} \mathrm{~Pb}$ and artificial radionuclides ${ }^{137} \mathrm{Cs}$, which are widely used in dating of recent sediments (0-150 years) [31-33], were applied following standard procedures. The samples for dating were sliced at $2-\mathrm{cm}$ intervals. ${ }^{210} \mathrm{~Pb}$ and ${ }^{137} \mathrm{Cs}$ were determined using an EG \& G Ortec Gamma Spectrometer. Total ${ }^{210} \mathrm{~Pb}$

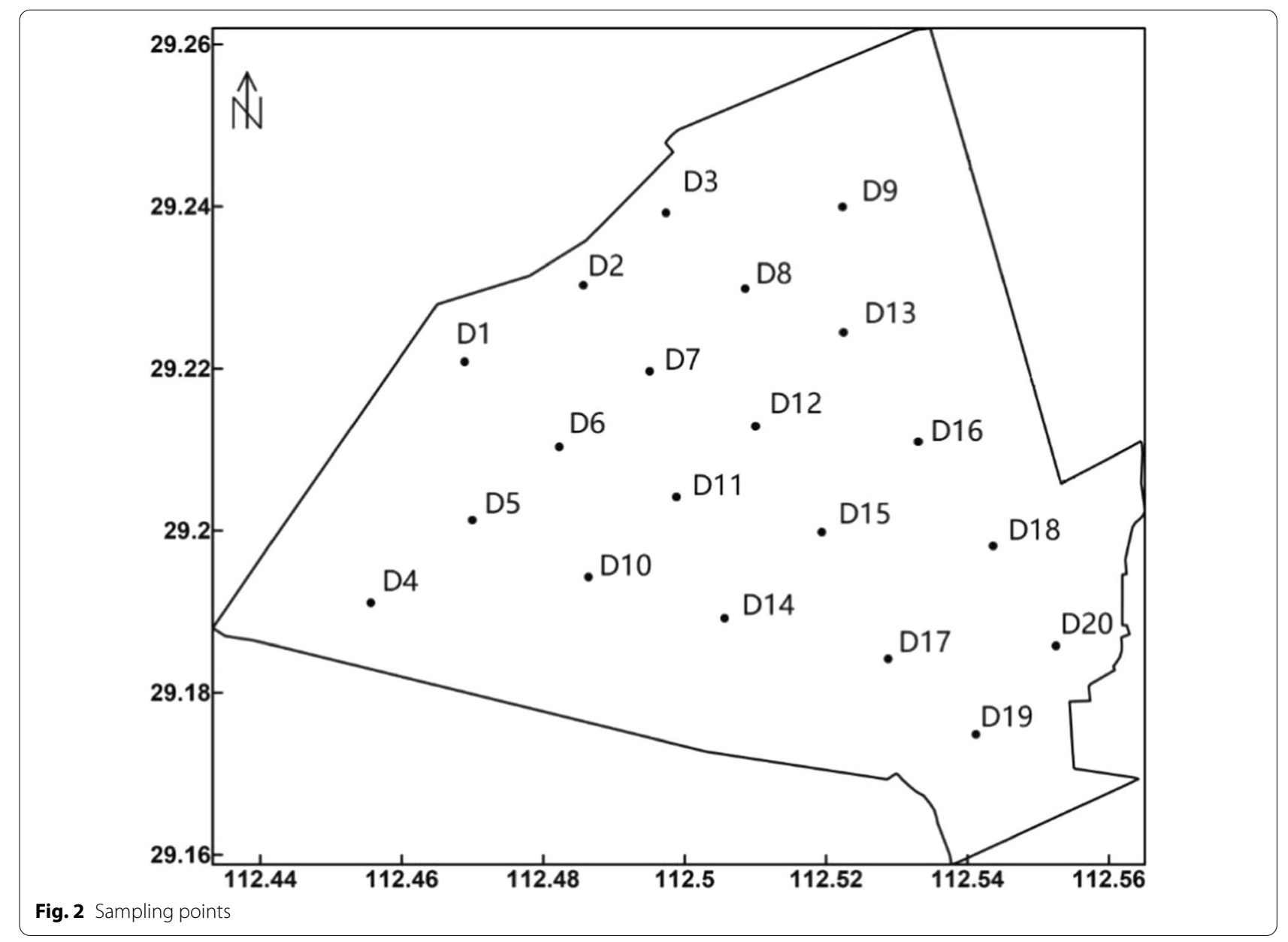


activity in sediments includes two components: supported ${ }^{210} \mathrm{~Pb}$, which is derived from in situ decay of the parent radionuclide ${ }^{226} \mathrm{Ra}$ (usually in radioactive equilibrium with ${ }^{226} \mathrm{Ra}$ ), and unsupported ${ }^{210} \mathrm{~Pb}\left({ }^{210} \mathrm{~Pb}_{\mathrm{ex}}\right)$, which is derived from the atmospheric flux. Considering potential disturbance in the catchment and compaction, the sedimentation rates were not constant, and the sedimentary age was thus estimated using the constant rate of supply (CRS) model [34].

The age $(T)$ of sediment of mass depth $m$, sedimentation rate (SAR), and dating error $\left(\sigma_{t}\right)$ were calculated using the formulas below [31]:

$$
\begin{aligned}
& T=\lambda^{-1} \ln (A(0) / A), \\
& \mathrm{SAR}=\lambda A / C_{m}, \\
& \sigma_{t}=\frac{1}{\lambda}\left[\left(\frac{\sigma_{A(0)}}{A(0)}\right)^{2}+\left(1-\frac{2 A}{A(0)}\right)\left(\frac{\sigma_{A}}{A}\right)^{2}\right]^{1 / 2},
\end{aligned}
$$

where $A(0)$ is the total inventory of ${ }^{210} \mathrm{~Pb}_{\mathrm{ex}}$ in the core, and $A$ is the excess inventory of ${ }^{210} \mathrm{~Pb}_{\mathrm{ex}}$ accumulated below depth $m$, both of which can be calculated by numerical integration of the concentration versus depth profile, and the uncertainties of $A(0)$ and $A$ are $\sigma_{A(0)}$ and $\sigma_{A}$, respectively. $\lambda$ is the ${ }^{210} \mathrm{~Pb}$ radioactive decay constant $(0.03114 / \mathrm{a}) . C_{m}$ is the ${ }^{210} \mathrm{~Pb}_{\mathrm{ex}}$ activity concentration in sediments at mass depth $m$. The ages of samples without direct date were calculated by interpolation.

\section{Reconstructions of diatom inferred-TP}

Diatom transfer functions were applied to the diatom data for sediment core. The abundance of diatom species in each sediment sample was expressed as a percentage. The reconstructions of the lake-water TP concentration were based on the diatom-TP transfer functions established from modern 45 lakes in neighboring provinces of China [11]. In the 45-lake calibration set, TP was selected because it explained the most variation of diatom distributions according to the canonical correspondence analysis. The inverse deshrinking weighted averaging regression and calibration method was employed to generate the transfer function. The final formula for TP was expressed as follows: $\log 10 \mathrm{TP}=-2.1295+2.0944 x i$, among which $x i$ represents the initial inferred TP for the $i$ sample. The transfer function model had a high correlation coefficient between inferred and observed TP $(\mathrm{R} 2$ jack $=0.75)$ and a low inference error (RMSEPjack $=0.17$ ). The reconstruction was done with CALIBRATE program [35].

\section{Ecosystem model application}

The Ecopath with Ecosim (EwE) model is a mass-based whole-ecosystem model that considers all trophic levels of the ecosystem and is mainly used to simulate ecosystem status and internal energy flows [36, 37]. It is used extensively to simulate the structures of aquatic food webs and to predict the impacts of fishery activities on fishery resources. There are several examples of its application, such as the construction of the food webs of the Great Lakes and the assessment of marine fishery resources [38, 39]. However, it has rarely been used to evaluate the ecological restoration of lakes. Given the need to facilitate the ecosystem-based restoration of eutrophic lakes, we used the EwE model in the present study $[40,41]$.

The Ecopath model is a static model that reflects the energy balance of each component of the ecosystem, and it has been developed from the steady-state model of Polovina [42]. Therefore, at any time, any organism or functional group in the ecosystem can satisfy the following relationship [43]:

$$
\begin{aligned}
\text { Production volume }= & \text { catch }+ \text { predation death } \\
& + \text { biomass accumulation } \\
& + \text { net migration } \\
& + \text { other deaths. }
\end{aligned}
$$

It can be expressed more concisely by the following Eq. (4):

$$
B_{i} \times(P / B)_{i} \times E E_{i}-\sum_{j} B_{j} \times(Q / B)_{j} \times D C_{i j}-Y_{i}=0,
$$

where $B_{i}$ is the biomass of the functional group $i ;(P / B)_{i}$ is the biological turnover rate of the functional group $i$, namely, the ratio of production to biomass, and its value is usually equal to the total mortality $Z$ of the population under static conditions; $E E_{i}$ is the ecological nutrition efficiency of the functional group $i$; $B_{j}$ is the biomass of the predatory functional group $j ;(Q / B)_{j}$ is the ratio of the consumption by the predatory function group $j$ to its biomass; $D C_{j i}$ is the proportion of food $i$ in the diet of predator $j$; and $Y_{i}$ is the fishing catch of group $i[44,45]$.

In the Ecopath model, $E E$ represents the proportion of yield lost due to predation or fishing in each group, which can be estimated after inputting the values of $B$, $P / B, Q / B$, and $D C$ of each functional group in the food web. We ensured that $E E<1$ after all the Ecopath model parameters had been input.

The energy balance formula in the Ecopath model is as follows:

$$
(P / Q)_{i}+(U / Q)_{i}+(R / Q)_{i}=1
$$

where $(P / Q)_{i}$ is the ratio of production to consumption; $(U / Q)_{i}$ is the ratio of unassimilated biomass to consumption; and $(R / Q)_{i}$ is the ratio of respiration to consumption. In the Ecopath model, the $(P / Q)_{i}$ value is calculated 
based on the input $(P / B)_{i}$ and $(Q / B)_{i}$ values. $(U / Q)_{i}$ is entered directly. $(R / Q)_{i}$ is calculated using Eq. (5). During the parameter adjustment, we ensured that the energy balance in the Ecopath model $(R / Q)$ was $>0$.

The uncertainty analysis and statistical analysis of the parameters and historical data for Ecopath model applied in Lake Datong have been described in detailed in our previous paper [46].

After the establishment of the Lake Datong Ecopath model, we divided the lake ecosystem into 17 functional groups (Additional file 1) according to their diet compositions, richness, and information accessibility of the organisms. Some species with important economic value or ecological functions were treated as a single functional group in order to analyze their relationship with other functional groups. A "debris group" was included in the functional groups. Debris is the sum of all inanimate organic matter in the ecosystem, including the carcasses of dead animals and macrophytes, animal feces, residues from feeding, and organic matter carried into the lake by rivers. It exists in the form of dissolved or solid particles.

The ratio of production to biomass $(P / B)$ of the Lake Datong functional groups was obtained following Guo et al. [47]. The ratio of fish consumption to biomass $(Q / B)$ was estimated using the empirical formula in Palomares et al. [48]. The aquatic food composition matrix data of Lake Datong were obtained through the analysis of food habits and the results of the analysis of the food habits of lake fish in other freshwater ecosystems in the Yangtze River Basin [49-51]. The ratio of production to consumption $(P / Q)$ of mollusks was obtained from Kao et al. [41]. The organic detrital biomass in the system was estimated with the linear model proposed by Pauly et al. [36]. $U / Q$ was set to its default values of 0.20 and 0.40 for carnivore and herbivore groups, respectively [45]. Following Kao et al. [41], we set $U / Q$ to 0.55 for mollusks. The units of biomasses were converted into $\mathrm{t} \mathrm{km}^{-2}$.

After the necessary parameters of all functional groups were entered, the model was debugged to achieve balance. Generally, the EE $(<1)$ and GE $(=P / Q)$ values estimated by the model needed to be between 0.1 and 0.3 to have physiological significance. We also used pre-balance (PREBAL) diagnostics to diagnose the model data [52]. As is included by the diagnosis, biomass should span 5-7 orders of magnitude; levels of biomass decline with increasing trophic level by $5-10 \%$ slope (on the log scale); $P / B$ and $Q / B$ ratios of predator groups should be lower than that of prey groups. According to Christensen et al. [45], to balance and optimize the model, its input parameters, especially the diet compositions, need to be fine-tuned. The input and output parameters and diet compositions of the Lake Datong model are listed in Additional file 2.

\section{Results \\ Succession of phytoplankton species composition in Lake Datong}

The abundance and biomass of phytoplankton in Lake Datong remained at a low level, while phytoplankton species have experienced great changes in the past 60 years (Table 1). Since the 1860 s, dinoflagellates have been the dominant species, accounting for $69.7 \%$ of all phytoplankton species; however, their abundance has decreased to less than $5 \%$ in recent years. In 2019, Chlorophyta formed the dominant species, accounting for 40-50\%; Euglenophyta increased from 0\% (prior to 2005) to $34.69 \%$ and then decreased rapidly to less than $10 \%$. Cyanobacteria increased from $0 \%$ in the 1960 s to $19.08 \%$ in the 2000 s, slowly increased to $23.75 \%$ in $2013-2014$, and then dropped to $\sim 20 \%$ in 2019. In addition, Bacillariophyta changed minimally from the 1960 s to $2008-2009$, increased to $27.59 \%$ by 2010 , and then decreased gradually to $16.24 \%$ by 2019 . The Shannon diversity index ( $H$-value) decreased from 2.045 in 2008-2009 to 1.24 in 2013 and then increased to 3.549 by 2019 . The Margalef richness index ( $D$-value) decreased from 3.11 in 2008-2009 to 0.75 in 2013 and then increased to 6.773 in 2019 . The Pielou evenness index ( $J$-value) decreased from 1.037 in 2008-2009 to 0.68 in $2012-2013$ and further decreased to 0.555 by 2019 (Table 1). In 2019, the results of the survey showed that the distribution of phytoplankton in Lake Datong had obvious spatial heterogeneity, with an overall trend of increasing from northeast to southwest (Additional file 3).

A total of 43 species from 21 genera were identified in the sedimentary column of Lake Datong. Among them, planktonic and benthic genera were dominant, and epiphytic genera were also common (Fig. 3), and Aulacoseira granulata was one of the dominant species. At $10 \mathrm{~cm}$ depth (approximately corresponding to the year 1980), the content of A. granulata and the diatom assemblage in the sedimentary column changed significantly. Below $10 \mathrm{~cm}$ depth, $A$. granulata was a dominant species, accounting for $60-80 \%$ of the total content, and it was found at the bottom of the borehole, where there were few diatoms. The populations of planktonic species with low nutrition, including $A$. ambigua and Cyclotella bodanica, and epiphytic species, including Fragilaria Capucina, Cocconeis placentula, Gyrosigma acuminatum, and Eunitia sp. accounted for less than 15\% of the total population. At a depth of $0-10 \mathrm{~cm}$, the proportion of $A$. granulata decreased rapidly. From 1 to $9 \mathrm{~cm}$ in the sediment column of Lake Datong, the content of $A$. 
Table 1 Phytoplankton succession in Lake Datong

\begin{tabular}{|c|c|c|c|c|c|c|c|}
\hline Years & $\begin{array}{l}\text { Number of } \\
\text { species }\end{array}$ & $\begin{array}{l}\text { Abundance and } \\
\text { biomass }\end{array}$ & $\begin{array}{l}\text { Dominant } \\
\text { species }\end{array}$ & $H$ value & $J$ value & $D$ value & References \\
\hline 1960 Winter & 5 domain & $2,180,000 \mathrm{ind} / \mathrm{L}$ & $\begin{array}{l}\text { Cyanobacteria: } \\
69.7 \%\end{array}$ & & & & [53] \\
\hline 1997 & $\begin{array}{l}8 \text { domain, } 64 \\
\text { genus }\end{array}$ & $1,780,000 \mathrm{ind} / \mathrm{L}$ & & & & & [54] \\
\hline 2005 Spring & $\begin{array}{l}6 \text { domain, } 12 \\
\text { genus }\end{array}$ & $\begin{array}{l}1,724,000 \mathrm{ind} / \mathrm{L} ; \\
3.156 \mathrm{mg} / \mathrm{L}\end{array}$ & & & & & {$[55]$} \\
\hline 2008-2009 & $\begin{array}{l}7 \text { domain, } 54 \\
\text { genus, } 98 \text { species }\end{array}$ & $\begin{array}{l}1,640,000 \text { ind/L } \\
\text { Summer; } \\
1,710,000 \text { ind/L } \\
\text { winter }\end{array}$ & & $\begin{array}{l}\text { Average value: } \\
2.045 \\
\text { Highest in winter: } \\
2.69 \\
\text { Lowest in sum- } \\
\text { mer: } 1.26\end{array}$ & $\begin{array}{l}\text { Average value: } \\
1.037 \\
\text { Highest in winter: } \\
1.27 \\
\text { Lowest in sum- } \\
\text { mer: } 0.69\end{array}$ & $\begin{array}{l}\text { Average value: } \\
3.11 \\
\text { Highest in spring: } \\
4.55 \\
\text { Lowest in } \\
\text { autumn: } 2.25\end{array}$ & {$[56]$} \\
\hline 2011 Summer & $\begin{array}{l}5 \text { domain, } 29 \\
\text { species }\end{array}$ & $8,560,000 \mathrm{ind} / \mathrm{L}$ & $\begin{array}{l}\text { Cyanobacteria: } \\
65.34 \%\end{array}$ & & & & [57] \\
\hline 2011-2012 & & $\begin{array}{l}1,850,000- \\
61,000,000 \text { ind/L }\end{array}$ & $\begin{array}{l}\text { Cryptophyta: } \\
50-90 \%\end{array}$ & & & & {$[58]$} \\
\hline 2013-2014 & $\begin{array}{l}7 \text { domain, } 80 \\
\text { species }\end{array}$ & $\begin{array}{l}6.58 \pm 0.66 \times 10^{4} \\
\text { ind } / \mathrm{L} ; \\
0.16 \pm 0.05 \mathrm{mg} / \mathrm{L}\end{array}$ & $\begin{array}{l}\text { Euglenophyta: } \\
\text { Euglena polymor- } \\
\text { pha; Cryptophyta: } \\
\text { Cryptomonas } \\
\text { ovata, Chroo- } \\
\text { monas acuta, } \\
\text { Bacillariophyta: } \\
\text { Cyclotlla caclotella; } \\
\text { Chlorophyta: } \\
\text { Chlorella vulgaris, } \\
\text { Chlamydomonas } \\
\text { incerta, Scenedes- } \\
\text { mus quadricauda }\end{array}$ & $\begin{array}{l}\text { Average value: } \\
1.24 \\
\text { Highest in August: } \\
2.08 \\
\text { Lowest in Novem- } \\
\text { ber: } 0.72\end{array}$ & $\begin{array}{l}\text { Average value: } \\
0.68 \\
\text { Highest in May: } \\
0.86 \\
\text { Lowest in Novem- } \\
\text { ber: } 0.31\end{array}$ & $\begin{array}{l}\text { Average value: } \\
0.75 \\
\text { Highest in August: } \\
1.15 \\
\text { Lowest in April: } \\
0.38\end{array}$ & [59] \\
\hline 2019 Summer & $\begin{array}{l}8 \text { phylum, } 197 \\
\text { species }\end{array}$ & $\begin{array}{l}1020765 \text { ind./L; } \\
0.871 \mathrm{mg} / \mathrm{L}\end{array}$ & Chlorophyta & $\begin{array}{l}\text { 3.241-3.806, Aver- } \\
\text { age value: } 3.549\end{array}$ & $\begin{array}{l}0.4463-0.587, \\
\text { Average value: } \\
0.555\end{array}$ & $\begin{array}{l}\text { 4.093-6.792, Aver- } \\
\text { age value: } 6.773\end{array}$ & - \\
\hline
\end{tabular}

$H$-index: Shannon diversity index; $J$-index: Pielou evenness index; $D$-index: Margalef richness index

granulata accounted for less than 5\%. Simultaneously, the content of diatoms began to increase and the numbers of eutrophic species such as Cyclotelaphanos thaliformis, C. meneghiniana, Stephanodiscus hantzschii, and S. minutulus began to increase.

\section{Succession of zooplankton species composition in Lake Datong}

The zooplankton in Lake Datong has been dominated by copepods since the 1960s. Among them, Calanoids along with a few rotifers and protozoa accounted for $84 \%$ of the total biomass. In Lake Datong, during the aquaculture period, the structure of its zooplankton community was characterized by small zooplankton protozoa, and the number of species, abundance, and biomass of rotifers accounted for a higher proportion than the large and medium-sized zooplankton Cladocera and Copepoda. Especially after 2011, a trend of miniaturization was increasingly evident. However, the number of species, biomass, and abundance of zooplankton surveyed have recently increased (Table 2). The average abundance of zooplankton was $19,904 \mathrm{ind} / \mathrm{L}$ and the average biomass was $966.38 \mathrm{mg} / \mathrm{L}$. Of these, the average abundance and biomass values of small zooplankton protozoa and rotifers combined were $19,870 \mathrm{ind} / \mathrm{L}$ and $5.471 \mathrm{mg} / \mathrm{L}$, respectively. In the case of large and medium-sized zooplankton, the average abundance and biomass of copepods were $31 \mathrm{ind} / \mathrm{L}$ and $912.91 \mathrm{mg} / \mathrm{L}$, respectively. The highest values of abundance and biomass were 41,100 ind/L and $6587.713 \mathrm{mg} / \mathrm{L}$, respectively at the sampling point D19. The minimum value was at D5, where the abundance was 9000 ind/L, and the biomass was $5.961 \mathrm{mg} / \mathrm{L}$. The abundance and biomass of zooplankton in Lake Datong demonstrated a significant variation in spatial distribution, with relatively high abundance in the east and relatively low abundance in the south (Additional file 4). The zooplankton $\mathrm{H}$-index in Lake Datong was 1.06 , with a range of $0.31-1.88$. The average value of the $\mathrm{D}$-index was 0.67 , ranging from 0.11 to 1.39 . The mean value of the $J$-index was 0.65 , with a range of $0.45-0.90$. 


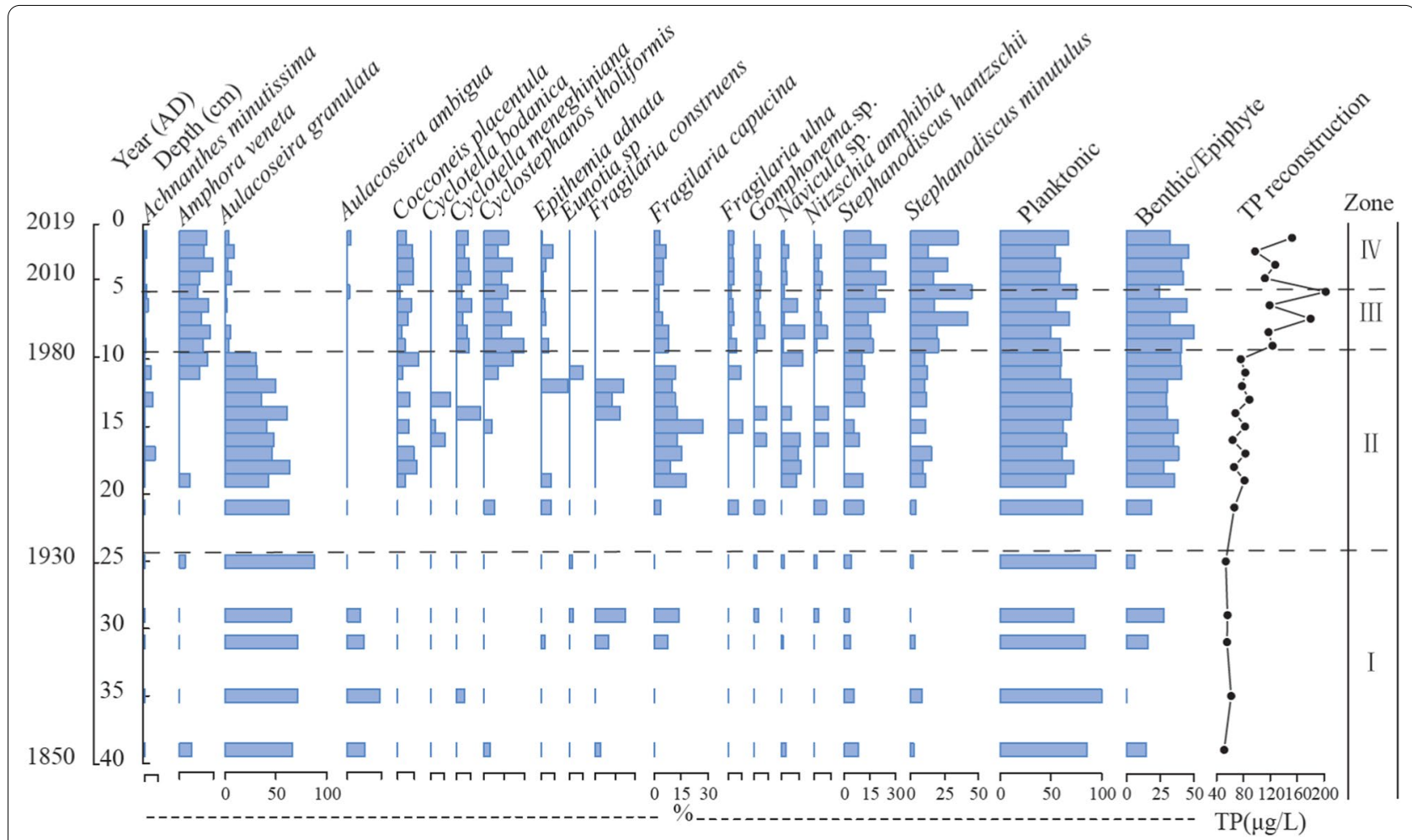

Fig. 3 Succession of diatom population in sediments of Lake Datong and reconstruction of the total phosphorus (TP) concentration in the water

Table 2 Zooplankton succession in Lake Datong

\begin{tabular}{|c|c|c|c|c|}
\hline Years & Number of species & Abundance and biomass & Dominant species & References \\
\hline 1960 Winter & & 371 ind/L & Calanoida: 84\% & [53] \\
\hline 1997 & 45 genus & $2930 \mathrm{ind} / \mathrm{L}$ & Rotifers, Protozoa & [54] \\
\hline 2005 Spring & 13 genus & $\begin{array}{l}2,205,000 \mathrm{ind} / \mathrm{L} ; \\
4.400 \mathrm{mg} / \mathrm{L}\end{array}$ & $\begin{array}{l}\text { Brachinous urceus, Daphnia pulex and Sinoca- } \\
\text { lanus sinensis }\end{array}$ & [55] \\
\hline 2011 Summer & 21 species & $89,307 \mathrm{ind} / \mathrm{L}$ & Rotifers & [57] \\
\hline $2011-2012$ & & $8000-125,000$ ind/L & Protozoa & [58] \\
\hline 2013-2014 & 20 genus, 46 species & $1013 \pm 198$ ind/L; $5.12 \pm 1.61$ mg/L & $\begin{array}{l}\text { Tintinnopsis sinensis, Brachionus diversicornis, } \\
\text { Asplanchna priodonta, Polyarthra trigla, Filinia } \\
\text { longiseta, Bosmina longirostris, Cyclops strenuus }\end{array}$ & [59] \\
\hline 2019 Summer & $\begin{array}{l}3 \text { phylum, } 15 \text { order, } 34 \\
\text { family, } 60 \text { genus, } 106 \\
\text { species }\end{array}$ & $\begin{array}{l}\text { Micro-zooplankton: } 31 \text { ind/L; } 912.91 \text { mg/L; } \\
\text { meso- and macro-zooplankton: 19,870 } \\
\text { ind/L;5.471 mg/L }\end{array}$ & $\begin{array}{l}\text { Copepods: Nauplii, Microcyclops varicans, Lim- } \\
\text { noithona sinensis, Cyclops strenuus, Thermocy- } \\
\text { clops hyalinus, Tropocyclops prasinus prasinus, } \\
\text { Psammophilocyclops trispinosus; Cladocera: } \\
\text { Bosmina longirostris, Bosminopsis deitersi, } \\
\text { Ceriodaphnia quadrangula, Bosmina coregoni, } \\
\text { Diaphanosoma leuchtenbergianum, Moina } \\
\text { micrura, Diaphanosoma brachyurum, Bosmina } \\
\text { fatalis Burckhardt. Protozoa: Strombidium } \\
\text { viride, Halteria grandinella, Pleurimema corna- } \\
\text { tum, Pyxidicula operculata, Arcella arenaria, } \\
\text { Pseudodifflugia gracilis, Difflugia urceolata, } \\
\text { Acanthocystis turfacea. Rotifers: Trichocerca } \\
\text { pusilla, Asplanchna brightwelli, Polyarthra } \\
\text { euryptera }\end{array}$ & - \\
\hline
\end{tabular}


Succession of mollusk species composition in Lake Datong In the winter of 1960, there were more than 21 species of mollusk in Lake Datong, including 11 species of Gastropoda and 10 species of bivalves. In terms of abundance and biomass, bivalves were dominant. The composition of mollusks in Lake Datong decreased to 15 species, belonging to five families, by 2008-2009 (Table 3). Bellamya purificata, Corbicula fluminea, and Unio douglasiae were the dominant species. During the intensive high-density aquaculture period, Lake Datong had a high abundance and high biomass of mollusks (Table 3). However, their average abundance and biomass presented evident temporal and spatial differences, showing a gradual increase over time from spring and summer to autumn and winter and a gradual decrease from northeast to southwest. During aquaculture period, Gyraulus albus, Segmentina nitida, and Radix, which prefer habitats with macrophytes, and Stenothyra divalis, Limnoperna lacustris, and Solenaia oleivara, which prefer the lotic habitat, disappeared. In addition, the dominant mollusk type changed from Lamellibranchia to Gastropoda. A recent survey in 2019 demonstrated that Lake Datong had seven species of mollusks from two orders, three families, and seven genera; one gastropod species and six bivalve species from one order, two families, and six genera. A total of 163 mollusks were collected during the investigation, and the total quantity of fish caught was $2824 \mathrm{~g}$. The number of ring snails of species B. purificata was 89 , and the catch was $188 \mathrm{~g}$, accounting for $6.66 \%$ of the total catch. Among bivalves, the number of the Lamellibranch species $U$. douglasiae was 50 . The catch of Cristaria plicata was the largest, weighing $1945 \mathrm{~g}$, accounting for 68.87\% of the total catch; C. fluminea was the least, weighing only $20 \mathrm{~g}$, accounting for only $0.71 \%$ of the total catch (Additional file 5). Comparing the distributions of mollusks in Lake Datong during aquaculture can shed light on their distinct temporal and spatial heterogeneity. Mollusks were mostly distributed in the northern and eastern parts of the lake, with a gradual decrease from northeast to southwest. There have been significant differences in their abundance and biomass in Lake Datong over the years. In 2019, our survey revealed that the biomass of large mollusks had dropped sharply (Table 3 ) to less than $90 \%$ of the biomass prevalent during aquaculture, as compared to previous years. Additionally, many sampling points did not present mollusk (only $55.56 \%$ of the sampling points collected mollusks), especially in the western waters where macrophytes are abundant.

\section{Succession of macrophyte species composition in Lake Datong}

In the early 1960s, Lake Datong maintained its natural lake form, with a $30 \%$ cover of macrophytes on the lake surface. The dominant species were Potamogeton wrightii Morong, Myriophyllum spicatum Linn, Vallisneria natans, and Hydrilla verticillata. Additionally, Ceratophyllum demersum, Najas minor, P. maackianus, Trapa bispinosa, and Nymphoides peltatum were associated species. Nelumbo nucifera, Azolla imbricata, Salvinia natans, Phragmites communis, and Leersia hexandra Swartz grew in the coastal shallow water marsh. In the 1980 s, the main species of macrophytes were $V$. natans, T. bispinosa, N. nucifera, P. wrightii Morong, C. demersum, $H$. verticillata, and Zizania latifolia. And, only one more species, $V$. natans, was found to be dominant. In 2000 , the coverage was only $10.60 \%$. During 2011-2012, the coverage of macrophytes was $~ 5 \%\left(420 \mathrm{hm}^{2}\right)$, and they were mainly distributed in the littoral zone of the lake and the river-lake confluence areas. Among them, submerged macrophytes accounted for $44 \%$, emerged macrophytes accounted for 30\%, floating-leaved macrophytes accounted for $14 \%$, and floating macrophytes

Table 3 Mollusk succession in Lake Datong

\begin{tabular}{|c|c|c|c|c|}
\hline Years & Number of species & Abundance and biomass & Dominant species & References \\
\hline 1960 Winter & 21 species & 232 ind. $/ \mathrm{m}^{2} ; 97.71 \mathrm{~g} / \mathrm{m}^{2}$ & $\begin{array}{l}\text { Hyriopsis cumingii, Arconaia lanceolate, } \\
\text { Lanceolaria glayana, Limnoperna lacustris, } \\
\text { Unio douglasiae, Corbicula fluminea, } \\
\text { Sphaerium sp, Solenia oleivora, Sphaerium } \\
\text { lacustre, Anodonta woodiana }\end{array}$ & [53] \\
\hline 1997 & 30 species & & & {$[54]$} \\
\hline $2008-2009$ & 5 family, 10 genus, 15 species & 598 ind. $/ \mathrm{m}^{2} ; 3637.71 \mathrm{~g} / \mathrm{m}^{2}$ & $\begin{array}{l}\text { Bellamya purificata, Corbicula fluminea, } \\
\text { Unio douglasiae }\end{array}$ & {$[60]$} \\
\hline 2011 Summer & 5 family, 13 species & 566 ind. $/ \mathrm{m}^{2} ; 913.375 \mathrm{~g} / \mathrm{m}^{2}$ & Bellamya purificata, Corbicula fluminea & {$[57]$} \\
\hline $2015-2017$ & & $\begin{array}{l}165.38 \text { ind. } / \mathrm{m}^{2}, 547.67 \mathrm{~g} / \mathrm{m}^{2}, 2015 ; 486.02 \\
\text { ind. } / \mathrm{m}^{2}, 854.77 \mathrm{~g} / \mathrm{m}^{2}, 2016 ; 546.70 \text { ind./ } \\
\mathrm{m}^{2}, 903.90 \mathrm{~g} / \mathrm{m}^{2}, 2017\end{array}$ & $\begin{array}{l}\text { Bellamya purificata, Corbicula fluminea, } \\
\text { Unio douglasiae, Lanceolaria gladiola, } \\
\text { Schistodesmus lampreyanus }\end{array}$ & {$[61]$} \\
\hline 2019 Summer & 2 order, 3 family, 7 genus, 7 species & 1146.67 ind. $/ \mathrm{m}^{2} ; 162.55 \mathrm{~g} / \mathrm{m}^{2}$ & Bellamya purificata, Cristaria plicata & - \\
\hline
\end{tabular}


accounted for $12 \%$ of the coverage. In 2017 , there were no macrophytes in the entire lake. Subsequently, by the end of 2017, comprehensive management of Lake Datong was undertaken and macrophytes were planted. By 2019, the coverage of macrophytes had reached $48 \%$ (Table 4).

As per the survey of macrophytes from July to November in 2019, seven species, six genera, and six families of macrophytes were recorded. There were five families, five genera, and five species of dicots, namely M. verticillatum, C. demersum, T. bispinosa, N. nucifera, and Halerpestes cymbalaria. The monocots had a representation of one family, one genus, and one species, namely, $H$. verticillata. $M$. verticillatum grows faster in the summer and slower in winter, making it tolerant of low temperatures (Additional file 6). In addition, macrophytes were mainly distributed in the western part of Lake Datong. In July, the macrophytes were found to be distributed over an area of $39.67 \mathrm{~km}^{2}$, which amounts to $48 \%$ of the total water surface area of Lake Datong. In September, they were distributed over an area of $27.2 \mathrm{~km}^{2}$, and in November over $23.99 \mathrm{~km}^{2}$, which amount to $33 \%$ and $29 \%$ of the total water surface area of Lake Datong, respectively. It can be observed that the range of distribution of macrophytes gradually reduced from July to November. The total biomass of macrophytes in Lake Datong in July, September, and November 2019 was 362,000 t, 173,000 $\mathrm{t}$, and 70,500 $\mathrm{t}$, respectively, also displaying a gradual decrease (Additional file 7).

\section{Succession of fish species composition in Lake Datong}

Before 1980, Lake Datong was utilized only for natural fishing, by feeding seedlings into the river; the development of aquaculture was established in the early 1980s. From 1981 to 1989 , the average annual fish production was $585 \mathrm{t}$. At that point, there were 109 species of fish belonging to 23 families and eight orders in Lake Datong. In 1989, fertilizers were beginning to be used in aquaculture. From 1990 to 1999, the average annual output of fish products from Lake Datong was $\sim 1000 \mathrm{t}$, and the highest annual output was above 1600 t. In 1997, there were eight orders, 23 families, and 109 species of fish. Since 2000, 4000-5000 t of various inorganic fertilizers have been utilized in Lake Datong annually. From 2000 to 2004, the average annual output of fish products from Lake Datong was $\sim 2000 \mathrm{t}$, with the highest annual output being $3000 \mathrm{t}$. After 2004, the annual input of various inorganic and compound fertilizers was 12,000$15,000 \mathrm{t}$, and the aquatic output of Lake Datong increased rapidly. The average annual output was $\sim 5000 \mathrm{t}$, and the highest annual yield exceeded 8000 t. In 2011, Lake Datong began to fence grass carp culture, adopt fertilization programs, and intensify cultivation. The fish yield that year exceeded 10,000 $\mathrm{t}$, with the yield maintained at $\sim 12,000 \mathrm{t}$. By 2012, the number of fish species declined to 45 species of 39 genera, 13 families, and seven orders. From 2011 to $2015,4500-5500 \mathrm{t}$ of fish was placed into Lake Datong every year, of which Hypophthalmichthys molitrix and H. nobilis accounted for $60 \%$ of the species, Ctenopharyngodon idella accounted for $30 \%$ of the species, and other fish species accounted for $\sim 10 \%$ (Table 5).

We found 28 species from 24 genera, eight families, and five orders in 2019. Among them, Cypriniformes had the most species with Cyprinidae, accounting for $89.29 \%$ of the total population, with 24 species belonging to 21

Table 4 Succession of macrophytes in Lake Datong

\begin{tabular}{|c|c|c|c|c|c|c|}
\hline Years & Number of species & Coverage rate & Distribution location & Biomass (wet weight) & Dominant species & References \\
\hline 1960 Winter & & $30 \%$ & Southern part & $1400-1760 \mathrm{~g} / \mathrm{m}^{2}$ & $\begin{array}{l}\text { Potamogeton wrightii } \\
\text { Morong, Myriophyllum } \\
\text { spicatum Linn, Vallisneria } \\
\text { natans, Hydrilla verticillata }\end{array}$ & {$[53]$} \\
\hline 1982 & More than 50 species & & & $2332.1 \mathrm{~g} / \mathrm{m}^{2}$ & Vallisneria natans & {$[62]$} \\
\hline 1997 & $\begin{array}{l}19 \text { family, } 41 \text { genus, } 86 \\
\text { species }\end{array}$ & $16.09 \%$ & & & & {$[54]$} \\
\hline 2000 & $\begin{array}{l}26 \text { family, } 39 \text { genus, } 56 \\
\text { species }\end{array}$ & $10.60 \%$ & West part & $1946.6 \mathrm{~g} / \mathrm{m}^{2}$ & & {$[63]$} \\
\hline $2011-2012$ & 24 genus, 24 species & $5 \%$ & West part & & $\begin{array}{l}\text { Vallisneria denseserrulata, } \\
\text { Potamogeton crispus, } \\
\text { Trapa bispinosa }\end{array}$ & {$[58]$} \\
\hline 2011 Summer & 24 genus, 24 species & $5 \%$ & & & & {$[57]$} \\
\hline 2019 Summer & $\begin{array}{l}6 \text { family, } 6 \text { genus, } 7 \text { spe- } \\
\text { cies }\end{array}$ & $30-40 \%$ & $\begin{array}{l}\text { West part and river- } \\
\text { lake confluences }\end{array}$ & $20 \mathrm{~g} / \mathrm{m}^{2}$ & $\begin{array}{l}\text { Ceratophyllum demersum, } \\
\text { Vallisneria natans, Trapa } \\
\text { bispinosa, Hydrilla verticil- } \\
\text { late, Myriophyllum verticil- } \\
\text { latum, Nelumbo nucifera }\end{array}$ & - \\
\hline
\end{tabular}


Table 5 Fish succession in Lake Datong

\begin{tabular}{lllll}
\hline Years & Number of species & Biomass & Dominant species & References \\
\hline 1997 & 8 order, 23 family, 109 species & $1500 \mathrm{t}$ & Hypophthalmichthys molitrix, Hypophthalmichthys nobilis & [54] \\
2011-2012 & 7 order, 13 family, 39 genus, 45 species & $16,000 \mathrm{t}$ & Hypophthalmichthys nobilis, Ctenopharyngodon idella & [58] \\
2011 Summer & 6 order, 12 family, 32 species & & Cyprinidae is dominant: 59.4\% & [57] \\
2019 Summer & 5 order, 8 family, 24 genus, 28 species & & Cyprinidae is dominant & - \\
\hline
\end{tabular}

genera, five families, and four orders, found in the eastern part of China. The total number and weight of the catch were 1486 fish and 43,684.6 g, respectively. Among them, the most abundant species were goblins and minnows, the total number and weight of the catch were 1059 fish and 21,486.7 g, respectively. There were 22 species belonging to 19 genera, five orders, five families, found in the northern part of the lake. The total number and weight of the catch were 935 and 53,860 g, respectively. Among them, the largest number and weight of the carnivorous fish Coilia brevicaudus were 248 and 5768 g, respectively, followed by Carassius auratus, which produced sticky eggs and omnivorous macrophyte food, with 193 fish weighing 16,022 g. There were 21 species belonging to 18 genera, three orders, and four families found in the western parts of the lake. The number and total weight of the catch were 1180 and 77,780 g, respectively. Among them, the most omnivorous macrophyte-feeding crucian carp was 598 and 47,983 g, in number and total weight of the catch, respectively, followed by the omnivorous macrophyte-eating Gobiocypris and minnows at 204 and $2552 \mathrm{~g}$, in number and weight, respectively (Additional file 8). Furthermore, there were no macrophyte $\mathrm{s}$ in the eastern lake area; however, we found more carnivorous fishes. The number of the Culter Basilewsky and Erythroculter were higher in the eastern lake area, while the number of $C$. brachygnathus was the largest in the northern lake area, followed by C. Basilewsky and Erythroculter. This is because of the few macrophytes in the eastern lake area, which is not conducive for the hiding of small fish but is for the predation and survival of carnivorous fish. Conversely, there were abundant macrophytes in the western lake area. Parabramis, Megalobrama, and Carassius, which produce sticky eggs and omnivorous macrophyte food were the most abundant, while the number of carnivorous fish was low. Several macrophytes provide abundant food for the omnivorous and herbivorous fishes, suitable habitat for their reproduction, and shelter for small fish, ensuring their abundance. However, the number of predatory fish in the lake was lower compared with other lakes of the same type.

\section{Historical nutrient change in Lake Datong}

Diatom inferred-total phosphorous (DI-TP) started around 1980 with a TP concentration increase from 66 to $202 \mu \mathrm{g} / \mathrm{L}$, and prior to 1930 , DI-TP was constant at $50-60 \mu \mathrm{g} / \mathrm{L}$. Four diatom assemblage zones were identified according to changing abundance of dominant taxa. Zone I (39-25 cm; pre-1930AD) was dominated by the planktonic A. granulata, with maximum abundances of $60 \%-80 \%$ and the lake was in a mesotrophic status. Zone II $(25-10 \mathrm{~cm}$; $1930-1980 \mathrm{AD})$ was characterized by the gradual decline of $A$. granulata and a slight increase of eutrophic planktonic species, indicating that Lake Datong presented a nutrient enrichment event (DI- TP fluctuated between 66 and $83 \mu \mathrm{g} / \mathrm{L})$. Zone III $(10-4 \mathrm{~cm}$; 1980-2010AD) was dominated by the eutrophic planktonic species $S$. hantzschii and $S$. minutulus, and a sudden decrease in $A$. granulata $(<10 \%)$. This period showed that Lake Datong had entered a eutrophic stage. Zone IV (the top $4 \mathrm{~cm}$; post-2010AD) was characterized by a slight decrease in the percentage of $S$. hantzschii and $S$. minutulus and the DI-TP reduced again.

The latest survey in 2019 revealed that TP was high between July and August, and low between September and November. Conversely, July and August are wet months, with a decrease in farmland activity, causing a large quantity of TP to accumulate in the ditches and eventually enter Lake Datong. However, in July and August, the growth of macrophytes in several areas of Lake Datong was too dense, resulting in an ecological imbalance in the water. Several macrophytes began to decompose. Additionally, the water temperature of the lake was high in July and August, which accelerated the decomposition rate. The nutrients absorbed by macrophytes during the growth period were released back to the water, causing secondary pollution (Additional file 9).

\section{Food web structure and trophic levels}

The trophic level of each functional group in the aquatic food web of Lake Datong varied between 1 (primary producer) and 3.685 (mandarin fish) (Table 6). Primary producers included submerged macrophytes and 
Table 6 Trophic level of each functional group in Lake Datong ecosystem

\begin{tabular}{lll}
\hline Rank & Function group & Trophic level \\
\hline 1 & Siniperca & 3.685 \\
2 & Erythroculter & 3.437 \\
3 & Pelteobagrus & 2.66 \\
4 & Coilia & 3.06 \\
5 & Megalobrama and Parabramis & 2.016 \\
6 & Cyprinus & 2.681 \\
7 & Carassius & 2.221 \\
8 & Hypophthalmichthys nobilis & 2.935 \\
9 & Hypophthalmichthys molitrix & 2.603 \\
10 & Small fish & 2.522 \\
11 & Mollusk & 2 \\
12 & Protozoans and Rotifers & 2 \\
13 & Cladocera & 2.02 \\
14 & Copepods & 2.02 \\
15 & Phytoplankton & 1 \\
16 & Submerged Macrophytes & 1 \\
17 & Detritus & 1 \\
\hline
\end{tabular}

phytoplankton. Carnivorous fish, such as mandarin fish and calamari, occupied higher trophic positions of the Lake Datong ecosystem.

The Ecopath model analysis demonstrated that the theoretical trophic level of Lake Datong in 2019 was trophic level IV (Fig. 4). The primary producers and detritus of the food web were defined as trophic level I, and the trophic level of consumers increased sequentially [43-45]. The trophic levels of the three primary producer functional groups in Lake Datong were trophic level I, and the trophic levels of mollusks and zooplankton were trophic level II. The energy flow of the Lake Datong food web had three main paths, including two pastoral and one detrital food chain. Debris was the main energy source of the Lake Datong aquatic food web (Fig. 4).

Lake Datong trophic level II had 11 functional groups. Among them, mollusks and small zooplankton were at trophic level II, while the proportions of crucian, bream, cladocerans and copepods at the integrated trophic level II were more than $50 \%$. Twelve functional groups occupied trophic level III. Among them, seven functional groups at the integrated trophic level III were more than $50 \%$. Eight functional groups occupied trophic level IV, and only three functional groups were in trophic level V. The proportion of mandarin fish was $3.09 \%$, and all other fish had proportions less than $1 \%$, indicating that the energy flow of trophic level $\mathrm{V}$ and above can be ignored.

\section{Discussion}

Succession and driving factors of the aquatic environment The sediment records of Lake Datong reveal the succession of its water environment, and the phosphorus trends in the sediment reflect the eutrophication trends (Fig. 3). According to the criteria of trophic status, Lake Datong has experienced four different stages of nutrition. The first stage was from 1847 to 1930: A. granulata was the dominant species of diatoms, and it usually inhabited moderately eutrophicated aquatic environments. Its high silicification degree, high sedimentation rate, and preference for strong disturbance in the water indicated strong hydrodynamic conditions. The sediment resuspension, which causes turbidity, reduces light incidence in the lake and thus affects primary productivity. At this period, the biomass of epiphytic diatoms and sample LOI was low. It is speculated that the water environment of the lake was suitable and the ecosystem was stable at this stage. The second stage was from 1930 to 1980: during this stage, people began large-scale reclamations around the lake, and more and more agricultural runoff flowed into Lake Datong with rainwater. DI-TP fluctuated in range from 50 to $60 \mu \mathrm{g} / \mathrm{L}$, and its average increased about $20 \mu \mathrm{g} / \mathrm{L}$ than the first stage. An interesting phenomenon is LOI reached a peak around 1945, when the impact of human activities was not very high. The probably reason is high coverage of macrophytes, whose litter leaves accumulated in sediment and contributed a high LOI value. Sediment historical data showed that the epiphytic diatoms Eunotia and Fragilaria increased significantly during this period, which implied that the quantity of macrophytes was large considering that epiphytic diatoms tend to adsorb on macrophytes. The dominant diatom was still A. granulata, with the maximum abundance observed in 1930-1940. In the winter of 1949, a dike was built on Lake Datong, which occupied the habitat for macrophytes. And then LOI decreased to extent after that. During the third stage, i.e., from 1980 to 2010, aquaculture and fertilizer farming began in the lake around 1989. During this period, the sediment TP increased rapidly, reaching its highest point around 2005, as much as $202 \mu \mathrm{g} / \mathrm{L}$. Moreover, compared with 1960, pH of the water in Lake Datong significantly increased (from $7.0-7.5$ to $8.4-8.8$ ), and the redox potential of watersediment interface layer decreased from +592 to 859 to -67.88 to $-110.80 \mathrm{mv}$. Electrical conductivity increased 17 -fold, from 0.138 to $2.363 \mathrm{mS} / \mathrm{cm}$. The lake environment shifted from oxidized to reduced $[60,62]$. At this period, A. granulata biomass dropped sharply, the biomass of epiphytic species such as Eunotia and Fragilaria 


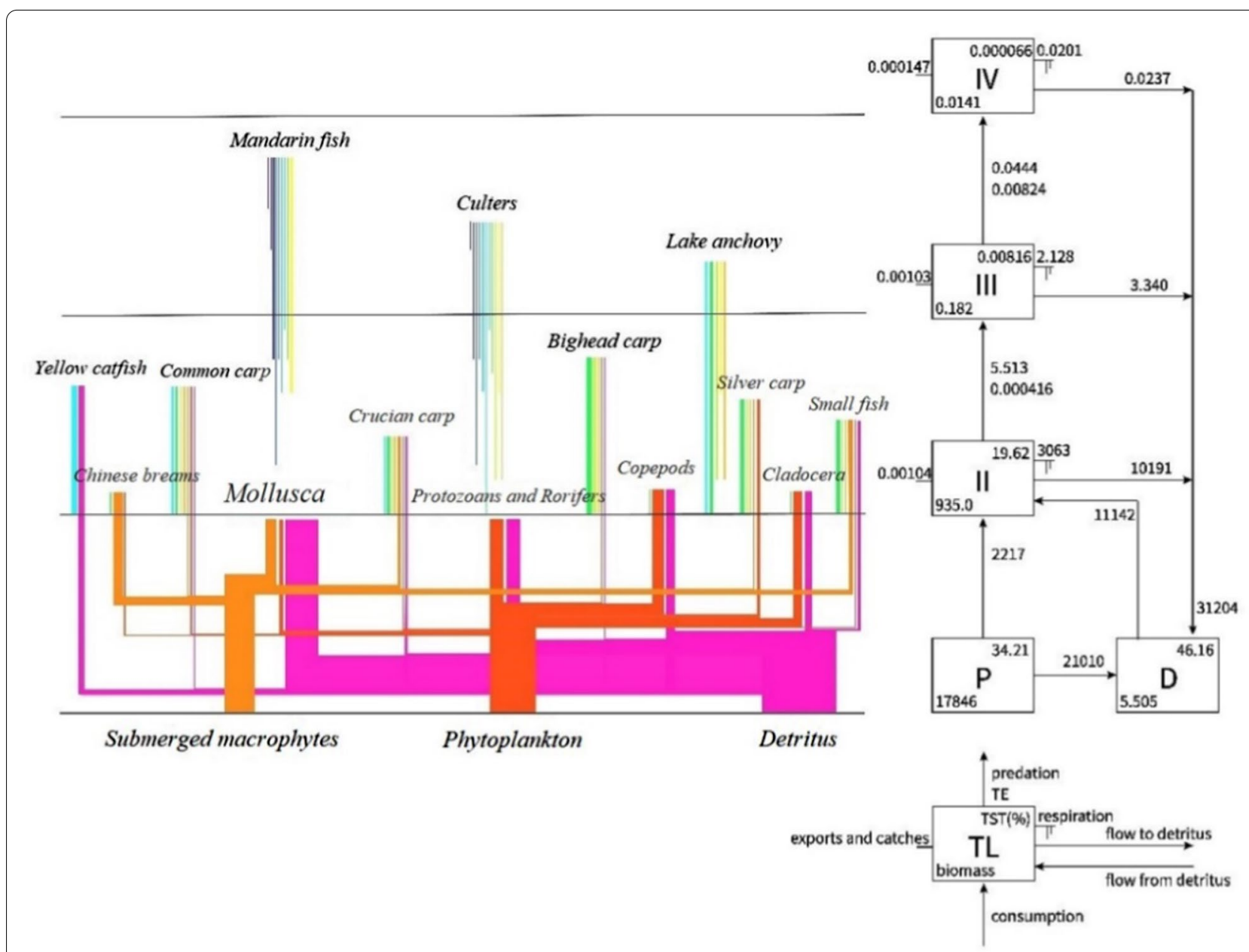

Fig. 4 Structure of the food web and energy flow diagram of Lake Datong. P: producer; D: detritus; TL: trophic grade; TST (\%): flux in the system (\%); TE: transfer efficiency

decreased gradually, and planktonic species such as $S$. hantzschii and S. minutulus were replaced by the dominant species. This was accompanied by the emergence of typical eutrophic species such as Cyclostephanos tholiformis and C. meneghiniana. These indicate that Lake Datong was in a eutrophic status. The fourth stage was after 2010: the trophic level of lake water declined (DITP ranged from 127 to $152 \mu \mathrm{g} / \mathrm{L}$ ) compared to the third stage. With more and more attention to environmental protection, large aquaculture in Lake Datong has been prohibited gradually by local government. And some ecological restoration measures, such as macrophytes restoration have been conducted.

\section{Succession and driving factors of aquatic communities}

There is little point-source pollution in Lake Datong Catchment. Agricultural non-point source pollution and input of exogenous physicochemical products are the main pollution sources [60]. During the development of aquaculture in Lake Datong from the 1980s to 2010s, eutrophication increased significantly. DI-TP increased significantly from $66-83 \mu \mathrm{g} / \mathrm{L}$ to $202 \mu \mathrm{g} / \mathrm{L}$, indicated that the trophic level of the lake increased significantly during this period and Lake Datong entered a eutrophic stage. According to the survey of Lake Datong in from 1960 to 2019 , Cyanobacteria increased from $0 \%$ in the $1960 \mathrm{~s}$ to $19.08 \%$ in the 2000 s, increased to $23.75 \%$ in 2013 to 2014, Bacillariophyta was $27.59 \%$ in 2010 , but decreased to $16.24 \%$ by 2019 (Table 1 ). The previous study showed that the intensification of eutrophication can easily cause the death of numerous aquatic species with poor hypoxic tolerance, while boost the rapid growth of aquatic species with the strong adaptive ability and lead to the gradual simplification of community structure [60]. This can cause the reduction of macroinvertebrates diversity and the proliferation of opportunistic species in the community [64]. Under eutrophic state, the pollution-tolerant 
and widespread taxa (oligochaetes and chironomids) usually became the predominant members [65].

Besides of eutrophication effect, restricting large-scale aquaculture activities from 2010 is another important factor. Especially for mollusk, its biomass decreased from $3637.71 \mathrm{~g} / \mathrm{m}^{2}$ in $2008-2009$ to $162.55 \mathrm{~g} / \mathrm{m}^{2}$ in 2019 , while its abundance increased from 598 ind. $/ \mathrm{m}^{2}$ in $2008-2009$ to $1146.67 \mathrm{ind} . / \mathrm{m}^{2}$ in 2019 (Table 3). During the restricting large-scale aquaculture activities, a lot of fish and mollusks with big shape have been removed from Lake Datong. Therefore, the biomass of mollusks dropped significantly. While the amount reduction of fish feeding mollusks benefit the reproduction of mollusks with small shape, so that the abundance of mollusks increased after restricting large-scale aquaculture activities.

\section{Food web structure}

In mature systems, the total primary production/total respiration (TPP/TR) is close to 1 , and the difference between the two is close to 0. For immature systems, respiration is lower than primary production, therefore, TPP/TR is greater than 1 . As the system matures, biomass can accumulate. Therefore, immature systems have the highest total primary production to total biomass (TPP/TB) values, which gradually decreases as the system matures. Connectance index $(\mathrm{CI})$ and system omnivorous index (SOI) reflect the complexity of a system's internal connections. The more mature a system is, the more complex the connections (food network) between its functional groups. Therefore, the CI and SOI are positively correlated with the maturity of the system. The more mature the ecosystem, the stronger the connections between the functional groups and the more stable the system. The CI and SOI of mature ecosystems are close to 1 . The maturity of the ecosystem was also evaluated using Finn's cycling index (FCI) and Finn's mean path length (FMPL) [66].

Table 7 General characteristics of Lake Datong and five other lakes of China

\begin{tabular}{|c|c|c|c|c|c|c|c|}
\hline & $\begin{array}{l}\text { Lake Taihu } \\
\text { (2008- } \\
\text { 2009) }\end{array}$ & $\begin{array}{l}\text { Lake Hongze } \\
(2010)\end{array}$ & $\begin{array}{l}\text { Dianchi (2009- } \\
\text { 2010) }\end{array}$ & $\begin{array}{l}\text { Lake Chaohu } \\
(2007-2010)\end{array}$ & Lake Gehu (2010) & $\begin{array}{l}\text { Lake Datong } \\
\text { (2019) }\end{array}$ & Unit \\
\hline $\begin{array}{l}\text { Sum of all consump- } \\
\text { tion }\end{array}$ & $16,760.9$ & 9544.719 & $61,614.648$ & 4486.47 & 2665.828 & $13,264.96$ & $\mathrm{t} /\left(\mathrm{km}^{2} \mathrm{a}\right)$ \\
\hline Sum of all exports & $15,299.5$ & 985.067 & $10,418.098$ & $16,796.60$ & 2184.73 & $20,061.23$ & $\mathrm{t} /\left(\mathrm{km}^{2} \mathrm{a}\right)$ \\
\hline $\begin{array}{l}\text { Sum of all respira- } \\
\text { tory flows }\end{array}$ & 4635.6 & 7138.957 & $15,675.121$ & 1308.45 & 829.088 & 3065.423 & $\mathrm{t} /\left(\mathrm{km}^{2} \mathrm{a}\right)$ \\
\hline $\begin{array}{l}\text { Sum of all flows into } \\
\text { detritus }\end{array}$ & $29,549.5$ & 5473.198 & $56,752.813$ & $18,411.37$ & 2892.898 & $31,203.67$ & $\mathrm{t} /\left(\mathrm{km}^{2} \mathrm{a}\right)$ \\
\hline $\begin{array}{l}\text { Total system } \\
\text { throughput (TST) }\end{array}$ & $66,245.5$ & $23,141.94$ & $144,752.81$ & $41,003.08$ & 8562.544 & $67,595.28$ & $\mathrm{t} /\left(\mathrm{km}^{2} \mathrm{a}\right)$ \\
\hline $\begin{array}{l}\text { Sum of all produc- } \\
\text { tion }\end{array}$ & $20,535.3$ & 8620.33 & $30,578.686$ & $17,937.42$ & 1974.82 & $26,214.06$ & $t /\left(k^{2} a\right)$ \\
\hline $\begin{array}{l}\text { Transfer efficiency } \\
\text { (TE) }\end{array}$ & 4.1 & 6.43 & 4.9 & 6.9 & 6.4 & 0.339 & $\%$ \\
\hline $\begin{array}{l}\text { Net primary produc- } \\
\text { tion (NPP) }\end{array}$ & $14,903.2$ & 8123.513 & $26,093.305$ & $17,703.42$ & 1815.238 & $23,126.66$ & $\mathrm{t} /\left(\mathrm{km}^{2} \mathrm{a}\right)$ \\
\hline $\begin{array}{l}\text { Total primary } \\
\text { production/total } \\
\text { respiration TPP/TR }\end{array}$ & 4.125 & 1.138 & 1.665 & 13.53 & 2.189 & 7.544 & \\
\hline $\begin{array}{l}\text { Net ecosystem } \\
\text { production (NEP) }\end{array}$ & $10,691.5$ & 984.556 & $10,418.093$ & $16,394.97$ & 986.151 & $20,061.23$ & $t /\left(k m^{2} a\right)$ \\
\hline $\begin{array}{l}\text { Total biomass } \\
\text { (excluding detritus) }\end{array}$ & & 1173.547 & 422.141 & 128.36 & 517.286 & 1.231 & $\mathrm{t} /\left(\mathrm{km}^{2} \mathrm{a}\right)$ \\
\hline $\begin{array}{l}\text { Connectance index } \\
\text { (Cl) }\end{array}$ & 0.188 & 0.195 & 0.194 & 0.20 & 0.219 & $18,781.15$ & \\
\hline $\begin{array}{l}\text { System omnivorous } \\
\text { index (SOI) }\end{array}$ & 0.041 & 0.089 & 0.061 & 0.092 & 0.189 & 0.083 & \\
\hline $\begin{array}{l}\text { Finn's cycling index } \\
(\mathrm{FCl})\end{array}$ & 18.3 & 6.77 & 39.980 & 3.32 & 7.99 & 17.55 & $\%$ \\
\hline $\begin{array}{l}\text { Finn's mean path } \\
\text { length (FMPL) }\end{array}$ & 3.32398 & 2.849 & 5.536 & 2.27 & 2.841 & 2.923 & \\
\hline References & [67] & [49] & [68] & [66] & [69] & - & \\
\hline
\end{tabular}


The ecosystem statistics and key indicators of Lake Datong and five other similar lakes are presented in Table 7, including community energetics, with the accumulation and continuous increase of the system biomass. The TPP/TR ratio of Lake Datong obtained from our model was 7.544 , and the net primary productivity was $20,061.23 \mathrm{t} /\left(\mathrm{km}^{2}\right.$.a). This demonstrates that there are many nutrients in the ecosystem of Lake Datong that have not been utilized. The TPP/TB of the Lake Datong ecosystem was 1.231 . The CI of Lake Datong was 0.277 and the SOI was 0.070 . This indicates that the structure of Lake Datong's food network ecosystem was fragile, with a low-level complexity of internal connections and low maturity. The FCI of Lake Datong was $17.55 \%$, and the FMPL was 2.923. Mature systems typically exhibit high levels of material recycling and long paths of nutrient flow in food chains [43]. Both the characteristics were low, which indicated low degrees of material circulation in the Lake Datong ecosystem. This means that the unused components of each functional group that entered the clastic formation were separated from the system due to mineralization and deposition.

\section{Limitations and scope for future research}

Ecological restoration is not an attempt to restore the same ecological community at a certain point in time, but to maximize the potential for restoration and continuous reorganization and adaptation of local species and communities to facilitate the restoration of the prior levels of various ecosystem functions [70]. There are currently only a few studies on the ecological restoration of aquaculture lakes. Zhang et al. [71] showed that with a 50\% reduction in aquaculture area, the TP concentrations of $58.7 \%$ of the lake in summer and $63.1 \%$ of the lake area in autumn are lower than $0.05 \mathrm{mg} / \mathrm{L}$, and macrophytes recovered in most areas of the lake. In the restoration process of shallow lakes in the middle and lower reaches of the Yangtze River in China, Lake Dianchi [72], Lake Donghu [73], and Lake Taihu [74, 75] showed suitable performance through the restoration of aquatic creatures to reduce eutrophication. However, under poor management, macrophytes were found to re-release large amounts of nutrients during the decay period, which can promote the eutrophication of lakes [76, 77]. Studies have shown that in the early stages of restoring shallow eutrophic lakes, the number of fish should be reduced, and macrophytes should be restored to reduce eutrophication. When the aquatic community tends to be stable, herbivorous and omnivorous fish should be stocked appropriately, and macrophytes should be harvested in the early stages of decline to maintain a healthy and sustainable development of the ecosystem [78].
In summary, in the process of aquatic ecological restoration of aquaculture lakes, we need to accurately control the aquatic biomass, increase the species diversity of aquatic creatures, improve the structure of the food chain, make the food chain more reticular, and enhance the integrity of the aquatic ecosystem through ecosystem analysis; at the same time, the best ecological restoration plan should be determined in combination with the research results concerning other vital aspects.

\section{Conclusions}

Four trophic succession stages of Lake Datong over the past 160 years were reconstructed, using the succession of sediment diatom populations and the TP concentration of the water. According to the criteria of trophic status, before 1930, Lake Datong was in a mesotrophic state (DI-TP ranged from 50 to $60 \mu \mathrm{g} / \mathrm{L}$ ). Between 1930 and 1980, the number of nutrient-tolerant species increased slightly, which indicates an increase in nutrient enrichment in Lake Datong (DI-TP ranged from 66 to $83 \mu \mathrm{g} / \mathrm{L}$ ). From the 1980s to 2010, eutrophication increased rapidly, especially since 2000 , where the eutrophic species had been dominant in the diatom assemblage (the annual average value of DI-TP was $202 \mu \mathrm{g} / \mathrm{L}$ ). After 2010, its trophic status decreased to some extent (DI-TP ranged from 127 to $152 \mu \mathrm{g} / \mathrm{L}$ ).

The ecosystem model of Lake Datong was successfully established for determining the nutrient structure and energy flow efficiency among its different nutrient levels after comprehensive management. The TPP/TR and TPP/TB values of the Lake Datong ecosystem were higher than those of the other five nearby lakes. However, TE, FCI, FMPL, CI, and SOI were lower, which indicates that Lake Datong ecosystem is in an unstable state, after restricting large-scale aquaculture activities and restoring macrophytes in recent years.

The succession of the water ecosystem of Lake Datong is reappeared by DI-TP analysis and historical reference data. At present, the consumer biomass of Lake Datong is at a relatively lower level, and the biomass of submerged macrophytes is higher, meaning a large quantity of primary producers had not been used by consumers, thus had not entered the food web, which consequently reduces the energy TE of the ecosystem. Future management needs to pay attention to making a suitable macrophyte harvest plan, stocking herbivorous and omnivorous fish, and establishing rational fishing, which can not only enhance the energy flows and nutrient cycling of the ecosystem, but also improve the food web structure. These results of the present study could be helpful for policymakers and local stakeholders in facilitating the assessment of the 
impact of environmental change in Lake Datong and can also be used to support similar aquaculture lakes, after comprehensive management planning and strategic decision-making.

\begin{abstract}
Abbreviations
Cl: Connectance index; DI-TP: Diatom inferred-total phosphorus; FCl: Finn's cycling index; FMPL: Finn's mean path length; ICP-AES: Inductively coupled plasma-atomic emission spectroscopy; LOI: Loss-on-ignition; TB: Total biomass; TE: Transfer efficiency; TL: Trophic grade; TN: Total nitrogen; TP: Total phosphorus; TPP: Total primary production; TR: Total respiration; TST: Flux in the system; SOI: System omnivorous index.
\end{abstract}

\section{Supplementary Information}

The online version contains supplementary material available at https://doi. org/10.1186/s12302-022-00595-2.

\begin{abstract}
Additional file 1: Lake Datong ecosystem functional group divisions and model input parameters and output parameters (bold text).

Additional file 2: Diet compositions of functional groups in Lake Datong ecosystem.

Additional file 3: Spatial distribution of the abundance and biomass of phytoplankton in Lake Datong in 2019.

Additional file 4: Spatial distribution of the abundance and biomass of zooplankton in Lake Datong.

Additional file 5: Survey results of mollusk in Lake Datong in 2019.

Additional file 6: Survey results of macrophytes in Lake Datong in 2019.

Additional file 7: Distribution map of macrophytes in Lake Datong.

Additional file 8: Statistics of fish resources in Lake Datong.

Additional file 9: Spatial distribution pattern of total phosphorus (TP).
\end{abstract}

\section{Acknowledgements}

Not applicable.

\section{Authors' contributions}

WH: conceptualization, methodology, formal analysis, investigation, writingoriginal draft; CHL: validation, resources, writing - review and editing, supervision; $\mathrm{CY}$ : validation, resources, writing - review and editing, supervision; HSC and XSL: formal analysis, investigation; JX: methodology, formal analysis; DLL: investigation. All authors read and approved the final manuscript.

\section{Funding}

This research was jointly supported by National Key Research and Development Program of China (2021YFC3201502) "Watershed non-point source pollution prevention and control technology and application demonstration" and the China-Germany Cooperation on Monitoring and Risk Assessment of Toxic and Harmful Pollutants in Taihu Lake (S2016G1115).

\section{Availability of data and materials}

The datasets used and/or analyzed during the current study are available from the corresponding author on reasonable request.

\section{Declarations}

Ethics approval and consent to participate

Not applicable.

\section{Consent for publication}

Not applicable.

\section{Competing interests}

The authors declare that they have no competing interests.

\section{Author details}

${ }^{1}$ National Engineering Laboratory for Lake Pollution Control and Ecological Restoration, State Environmental Protection Key Laboratory for Lake Pollution Control, Chinese Research Academy of Environmental Sciences, Beijing 100012, China. ${ }^{2}$ Yunnan Key Laboratory of Pollution Process and Management of Plateau Lake-Watershed, Yunnan Research Academy of Eco-Environmental Sciences, Kunming 650034, China. ${ }^{3}$ Institute of Hydrobiology, Chinese Academy of Sciences (CAS), Wuhan 430072, China. ${ }^{4}$ School of Geographical Sciences and Remote Sensing, Centre for Climate and Environmental Changes, Guangzhou University, Guangzhou 510006, China. ${ }^{5}$ College of Marine Life Sciences, Ocean University of China, Qingdao 266003 , China. ${ }^{6}$ College of Animal Science and Technology, Hunan Agricultural University, Changsha 410128, China.

Received: 19 September 2021 Accepted: 29 January 2022

Published online: 22 February 2022

\section{References}

1. Food and Agriculture Organization (FAO) (2015) Statistical pocketbook world food and agriculture. Food and Agriculture Organization, Rome

2. Food and Agriculture Organization (FAO) (2017) Fishery and aquaculture statistics. Food and Agriculture Organization, Rome

3. Ministry of Agriculture (MOA) (2019) China fishery statistical yearbook. China's Ministry of Agriculture. Fishery Bureau, Ministry of Agriculture of the People's Republic of China, China Agriculture Press, Beijing, China

4. Wu M, Huang S, Zang C, Du S, Scholz M (2012) Release of nutrient from fish food and effects on Microcystis aeruginosa growth. Aquac Res 43(10):1460-1470

5. Wang LM, Liu DW (2008) Influence of cage culture on water quality in Panjiakou Reservoir. Hebei Fish 6:42-44+49

6. Tang X, Li R, Han D, Scholz M (2020) Response of eutrophication development to variations in nutrients and hydrological regime: a case study in the Changjiang River (Yangtze) Basin. Water 12(6):1634

7. Guo L, Li Z (2003) Effects of nitrogen and phosphorus from fish cageculture on the communities of a shallow lake in middle Yangtze River basin of China. Aquaculture 226(1-4):201-212

8. Cai CF, Gu XH, Ye YT, Yang C, Dai X, Chen D, Yang C (2012) Assessment of pollutant loads discharged from aquaculture ponds around Taihu Lake, China. Aquacult Res 44(5):795-806

9. Morata T, Falco S, Gadea I, Sospedra J, Rodilla M (2015) Environmental effects of a marine fish farm of gilthead seabream (Sparus aurata) in the NW Mediterranean Sea on water column and sediment. Aquac Res 46(1):59-74

10. Srithongouthai S, Tada K (2017) Impacts of organic waste from a yellowtail cage farm on surface sediment and bottom water in Shido Bay (the Seto Inland Sea, Japan). Aquaculture 471:140-145

11. Yang X, Anderson NJ, Dong X, Shen II (2008) Surface sediment diatom assemblages and epilimnetic total phosphorus in large, shallow lakes of the Yangtze floodplain: their relationships and implications for assessing long-term eutrophication. Freshwater Biol 53(7):1273-1290

12. Kaspar HF, Hall GH, Holland AJ (1988) Effects of sea cage salmon farming on sediment nitrification and dissimilatory nitrate reductions. Aquaculture 70(4):333-344

13. Machate O, Dellen J, Schulze T, Wentzky VC, Krauss M, Brack W (2021) Evidence for antifouling biocides as one of the limiting factors for the recovery of macrophyte communities in lakes of Schleswig-Holstein. Environ Sci Eur 33(1):1-12

14. Bennion H, Johnes P, Ferrier R, Phillips G, Haworth E (2005) A comparison of diatom phosphorus transfer functions and export coefficient models as tools for reconstructing lake nutrient histories. Freshw Biol 50(10):1651-1670 
15. Battarbee R, Jones V, Flower R, Cameron N, Bennion H, Carvalho L, Juggins S (2001) Diatoms. In: Smol J, Birks J, Last W, Bradley R, Alverson $\mathrm{K}$ (eds) Tracking environmental change using lake sediments, vol 3. Terrestrial, algal, and siliceous indicators. Springer, Netherlands, pp $155-202$

16. Li XP, Chen XH, Dong XH, Dong Z, Sun DP (2012) Nutrient dynamics over the past 100 years and its restoration baseline in Dianshan Lake. Environ Sci 33(10):3301-3307

17. Dong XH, Yang XD, Wang R, Pan H (2005) A diatom-total phosphorus transfer function for lakes in the middle and lower reaches of Yangtze River. J Lake Sci 18(1):1-12

18. Hall Rl, Smol JP (1992) A weighted-averaging regression and calibration model for inferring total phosphorus concentration from diatoms in British Columbia (Canada) lakes. Freshw Biol 27(3):417-434

19. Anderson N (1997) Historical changes in epilimnetic phosphorus concentrations in six rural lakes in Northern Ireland. Freshwater Biol 38(2):427-440

20. Smol JP, Stoermer EF (2010) The diatoms: applications for the environmental and earth sciences. Cambridge University Press

21. Sochuliaková L, Sienkiewicz E, Hamerlík L, Svitok M, Fidlerová D, Bitušík P (2018) Reconstructing the trophic history of an alpine lake (High Tatra Mts.) using subfossil diatoms: disentangling the effects of climate and human influence. Water Air Soil Pollut 229(9):1-12

22. Zhou Q, Huang WR, Zhou NQ, Teng F, Wang BB, Liu XQ, Xie S, Shen XP (2015) Numerical modeling of reducing total nitrogen through inflow from channels in Lake Datong, China. In Proceedings of the International Forum on Energy, Environment Science and Materials, Shenzhen, China, 25-26 September. pp. 1268-1274

23. Hu W, Wei WW, Ye C, Li CH, Zheng Y, Shi XG, Chen HS (2021) Determining the optimal biomass of macrophytes during the ecological restoration process of eutrophic shallow lakes. Water 13(21):3142

24. Jian YX, Wang JB, He GQ, Chen JK (2002) A comparative study on aquatic plant diversity and its long-term changes in the three lakes of Dongtinghu district in China. Acta Hydrobiol Sin 26:160-167

25. Modigh M, Castaldo S (2005) Effects of fixatives on ciliates as related to cell size. J Plankton Res 27:845-849

26. Zhang X, Xie P, Chen F, Li SX, Qin J (2010) Driving forces shaping phytoplankton assemblages in two subtropical plateau lakes with contrasting trophic status. Freshw Biol 52:1463-1475

27. Long SX, Hamilton PB, Yang Y, Wang S, Chen C, Tao R (2018) Differential bioaccumulation of mercury by zooplankton taxa in a mercury-contaminated reservoir Guizhou China. Environ Pollut 239:147-160

28. Environmental Monitoring of China (2013) Practical manual of environmental monitoring method standards of China. China Environmental Science Press, Beijing

29. Krammer K, Lange-Bertalot H (1886-1991) Susswasserflora von Mitteleuropa. Gustav Fischer Verlag, Stuttgart and Jena. pp 149-472

30. Liao XH, Li CH, Dong XH, Wei WW (2021) Environmental evolution of Datong Lake over the past 160 years and its nutrient baseline. Acta Hydrobiol Sin 45:206-215 (in Chinese)

31. Xian HB, Dong XH, Li Y, Zhan N, Jeppesen E (2022) High-resolution reconstruction of typhoon events since $\sim 1850$ CE based on multi-proxy sediment records in a coastal lagoon, South China. Sci Total Environ 803:150063

32. Corcoran M, Sherif MI, Smalley C, Li A, Rockne KJ, Giesy JP, Sturchio NC (2018) Accumulation rates, focusing factors, and chronologies from depth profiles of 210Pb and 137Cs in sediments of the laurentian Great Lakes. J Great Lakes Res 44:693-704

33. Mizugaki S, Nakamura F, Araya T (2006) Using dendrogeomorphology and $137 \mathrm{Cs}$ and $210 \mathrm{~Pb}$ radiochronology to estimate recent changes in sedimentation rates in Kushiro Mire, Northern Japan, resulting from land use change and river channelization. CATENA 68(1):25-40

34. Appleby P (2002) Chronostratigraphic techniques in recent sediments. In: Last WM, Sol JP (eds) Tracking environmental change using lake sediments. Developments in paleoenvironmental research, vol 1. Springer, Dordrecht, pp 171-203

35. Juggins S (1997) CALIBRATE version 0.70-A C++ problem for analysing and visualizing species environment relationships and for predicting environmental values from species assemblages, user guide version 1.0, UK: Department of Geography, University of Newcastle: 1-23
36. Pauly D, Bartz MLS, Palomares MLD (1993) Improved construction, parametrization and interpretation of steady-state ecosystem models. In: Christensen V, Pauly D (eds) Trophic Models of Aquatic Ecosystems. ICLARM, Penang

37. Plagányi ÉE (2007) Models for an Ecosystem Approach to Fisheries, Food and Agriculture Organization of the United Nations. Rome, Italy

38. Nakamura K, Tockner K, Amano K (2008) River and wetland restoration: Lessons from Japan. Bioscience 56:419-429

39. Wu K (2015) The evolutional characteristics of water environment and total amount control of pollutant in Lake Datong Basin based on GIS. Master's Thesis, Hunan University of Science and Technology, Xiangtan, China

40. Heymans JJ, Coll M, Libralato S, Morisette L, Christensen V (2014) Global patterns in ecological indicators of marine food webs: a modelling approach. PLoS ONE 9(4):e95845

41. Kao YC, Adlerstein S, Rutherford E (2014) The relative impacts of nutrient loads and invasive species on a Great Lakes food web: an Ecopath with Ecosim analysis. J Great Lakes Res 40:35-52

42. Grigg RW, Polovina JJ, Atkinson MJ (1984) Model of a coral reef ecosystem. Coral Reefs 3:1-11

43. Christensen V, Walters J (2004) Ecopath with Ecosim: methods, capabilities and limitations. Ecol Modell 172(2-4):109-139

44. Christensen V, Walters CJ, Pauly D (2005) Ecopath with Ecosim: a user's guide. Fisheries Centre of University of British Columbia, Vancouver, Canada

45. Christensen V, Walters CJ, Pauly D (2008) Ecopath with Ecosim version 6 user guide. University of British Columbia, Vancouver, Canada

46. Liu ZY, Meng XL, Li ZF, Zhang JQ, Xu J, Yin SL, Xie ZC (2020) Diversity assessment and protection strategies for the mollusk community in the southern Dongting Lake. Biodivers Sci 28(2):155-165

47. Guo C, Ye S, Le KS, Liu J, Zhang T, Yuan J, Li Z (2013) The need for improved fishery management in a shallow macrophytic lake in the Yangtze River basin: evidence from the food web structure and ecosystem analysis. Ecol Modell 267:138-147

48. Palomares ML, Pauly D (1998) Predicting food consumption of fish populations as functions of mortality, food type, morphometrics, temperature and salinity. Mar Freshw Res 49(5):447-453

49. Guo C, Chen Y, Li W, Xie S, Lek S, Li Z (2018) Food web structure and ecosystem properties of the largest impounded lake along the eastern route of China's South-to-North Water Diversion Project. Ecol Inform 43:174-184

50. Wang Y, Kao YC, Zhou Y, Zhang H, Yu X, Lei G (2019) Can water level management, stock enhancement, and fishery restriction offset negative effects of hydrological changes on the four major Chinese carps in China's largest freshwater lake? Ecol Model 403:1-10

51. Zhang TL (2005) Life-history strategies, trophic patterns and community structure in the fishes of Lake Biandantan. Institute of Hydrobiology, The Chinese Academy of Sciences, Wuhan

52. Link JS (2010) Adding rigor to ecological network models by evaluating a set of pre-balance diagnostics: a plea for PREBAL. Ecol Modell 221:1580-1591

53. Lu FY, Zhang ZS, Qiu CQ, Wo ZT, Wang GS (1964) A preliminary report on the hydrobiological conditions and recent sediment of lake Datong. Oceanologia Limnologia Sin 6(4):323-330

54. Li HX (1997) Present situation and development of Fisheries in Lake Datong. Curr Fish 1:5-6

55. Jin H, Xiang JG, Tang WX (2005) Investigation on plankton and fish productivity in Lake Datong fishing ground. Curr Fish 30(7):22-24

56. Li DL, Zhang T, Xiao TY, Yu JB, Wang HQ, Chen KJ, Liu AM, Liu AM (2012) Phytoplankton's community structure and its relationships with environmental factors in an aquaculture lake, Lake Datong of China. Chin J Appl Ecol 23(8):2107-2113

57. Bo Y (2013) College of Animal Science and Technology, Hunan Agricultural University

58. Yang PH, Chen HW, Yu Y, Liu LG, Zou W, Wang WB, Li ZJ, Liu AM, Cao M, Huang CH, Luo YS (2013) An investigate of the natural resources and the strategic thinking of comprehensive development and utilization in Lake Datong. J Hunan Univ Arts Sci (Nat Sci Ed) 1:21-27 
59. Gao ZH (2016) Plankton community structure and its relationships with environmental factors in Lake Datong. Hunan Agricultural University, College of Animal Science and Technology

60. Li DL, Zhang T, Yu JB, Mao X, Wang H, Chen K, Liu A, Li Z, Xiao T (2011) Temporal and spatial distributional patterns of mollusk in a typical aquacultural lake-Lake Datong. Acta Hydrobiol Sin 35(6):946-954

61. Zhu PF (2018) Survey of molluscs resources in Lake Datong and effect of fish-polyculture on the community structure of plankton. Hunan Agricultural University, College of Animal Science and Technology

62. Li HX, Liu AM (1983) Preliminary investigation of aquatic plant resources in Lake Datong and discussion on fishery utilization. Curr Fish 3:28-29

63. Xing JY, Bo WJ, Qing HG, Kuan CJ (2002) A comparative study on aquatic plant diversity and its long-term changes in the three lakes of Dongtinghu district in China. Acta Hydrobiol Sin 26(2):160-167

64. Zhang Y, Leung JY, Zhang Y, Cai Y, Zhang Z, Li K (2021) Agricultural activities compromise ecosystem health and functioning of rivers: insights from multivariate and multimetric analyses of macroinvertebrate assemblages. Environ Pollut 275:116655

65. Zhang J, Wang C, Jiang X, Song Z, Xie Z (2020) Effects of human-induced eutrophication on macroinvertebrate spatiotemporal dynamics in Lake Dianchi, a large shallow plateau lake in China. Environ Sci Pollut Res 27(12):13066-13080

66. Liu ES, Li YK, Zang RW, Wang H (2014) A preliminary analysis of the ecosystem structure and functioning of Lake Chaohu based on Ecopath model. J Fish China 38(3):417-425

67. Li YK, Liu ES, Wang H, Yi G (2014) Analysis on the ecosystem structure and function of Lake Taihu based on Ecopath model. J Appl Ecol 25(7):2033-2040

68. Shan K, Li L, Wang XX, Wu Y, Hu L, Yu G, Song L (2014) Modelling ecosystem structure and trophic interactions in a typical cyanobacterial bloomdominated shallow Lake Dianchi, China. Ecol Modell 291(2014):82-95

69. Jia PQ, Hu ZJ, Wu Z, Liu QG, Wu ZX, Kong YJ, Zhu Y (2013) Quantitative analysis on the structure and function of the Gehu lake ecosystem based on Ecopath modeling. Resour Environ Yangtze Basin 22(2):189-197

70. Gann GD, McDonald T, Walder B, Aronson J, Nelson CR, Jonson J, Hallett JG, Eisenberg C, Guariguata MR, Liu J, Hua F (2019) International principles and standards for the practice of ecological restoration. Restor Ecol 27(S1):S1-S46

71. Zhang T, Ban X, Wang X, Cai X, Li E, Wang Z, Yang C, Zhang Q, Lu X (2017) Analysis of nutrient transport and ecological response in Honghu Lake, China by using a mathematical model. Sci Total Environ 575:418-428

72. Wang Z, Zhang Z, Zhang J, Zhang Y, Liu H, Yan S (2012) Large-scale utilization of water hyacinth for nutrient removal in Lake Dianchi in China: the effects on the water quality, macrozoobenthos and zooplankton. Chemosphere 89(10):1255-1261

73. Qiu DR, Wu ZB, Liu BY, Deng J, Fu G, He F (2001) The restoration of aquatic macrophytes for improving water quality in a hypertrophic shallow lake in Hubei Province, China. Ecol Eng 18(2):147-156

74. Gao HL, Shi QY, Qian X (2017) A multi-species modelling approach to select appropriate submerged macrophyte species for ecological restoration in Gonghu Bay, Lake Taihu, China. Ecol Modell 360:179-188

75. Luo J, Li X, Ma R, Li F, Duan H, Hu W, Qin B, Huang W (2016) Applying remote sensing techniques to monitoring seasonal and interannual changes of aquatic vegetation in Taihu Lake, China. Ecol Indic 60:503-513

76. Carignan R, Kal J (1982) Phosphorus release by submerged macrophytes: significance to epiphyton and phytoplankton. Limnol Oceanogr 27(3):419-427

77. Wu S, He S, Zhou W, Gu J, Huang J, Gao L, Zhang X (2017) Decomposition characteristics of three different kinds of aquatic macrophytes and their potential application as carbon resource in constructed wetland. Environ Pollut 231(1):1122-1133

78. Zhu K, Wu Y, Li C, Xu J, Zhang M (2020) Ecosystem-based restoration to mitigate eutrophication: a case study in a shallow lake. Water 12(8):2141

\section{Publisher's Note}

Springer Nature remains neutral with regard to jurisdictional claims in published maps and institutional affiliations.

\section{Submit your manuscript to a SpringerOpen ${ }^{\circ}$ journal and benefit from:}

- Convenient online submission

- Rigorous peer review

- Open access: articles freely available online

- High visibility within the field

- Retaining the copyright to your article

Submit your next manuscript at $\boldsymbol{\nabla}$ springeropen.com 